\title{
Antiulcer Effect of Commiphora molmol Engl. (Burceraceae) Oleo-gum-resin and its Interaction with Ranitidine, as Demonstrated by Histological Studies
}

\author{
Abdulrahman A. I. AL-Yahya \\ College of Applied Medical Sciences, Shaqra University, Saudi Arabia. \\ DOI: http://dx.doi.org/10.13005/bbra/1859
}

(Received: 08 August 2015; accepted: 16 September 2015)

\begin{abstract}
Myrrh (Commiphora molmol Engl.) is a widely used herb throughout the world. The present study evaluates the ulcer healing effect of myrrh and effect of co-administration of myrrh with ranitidine on ulcer healing in acetic acid induced chronic gastric ulcers in rats. Myrrh was administered at two different doses of $500 \mathrm{mg} / \mathrm{kg}$ and $1000 \mathrm{mg} / \mathrm{kg}$ orally while ranitidine was given at a dose of $50 \mathrm{mg} / \mathrm{kg}$ orally. Myrrh increased the healing of the ulcers in a dose-dependent manner. It increased the ulcer score and ulcer index compared to vehicle treated animals. Histological studies of the ulcerated tissues supported the macroscopic findings as demonstrated by regeneration of surface epithelium. As expected, ranitidine increased gastric ulcer healing while the combination of ranitidine and high dose of myrrh $(1000 \mathrm{mg} / \mathrm{kg}$, p.o $)$ showed increased ulcer healing compared to ranitidine alone. It was concluded that myrrh increases gastric ulcer healing and potentiates the effect of ranitidine on ulcer healing in rats.
\end{abstract}

Key words: myrrh, acetic acid, ulcer index, ulcer score

Commiphora molmol Engl. (Burseraceae), known commonly as "myrrh" or Murr (in Arabic) is one of the most common herbs. It is reported to possess several pharmacological activities that includes antihypertensive ${ }^{1}$, hypolipidemic ${ }^{2}$, antiinfective ${ }^{3}$, antiulcer ${ }^{4}$ and anticancer effects ${ }^{5}$.

Myrrh is reported to possess healing benefits during injuries ${ }^{6}$. It has been reported for gastric ulcer preventive effect earlier wherein it is reported to prevent development of gastric ulcers induced by necrotizing agents and pylorus ligation in rats ${ }^{1}$. However, so far there is no report on the effect of myrrh on ulcer healing, an effect that correlates clinically with effect on ulcer patients

\footnotetext{
* To whom all correspondence should be addressed. Tel.: +966-0531339880;

E-Mail: alya7ya@su.edu.sa
}

consuming myrrh. Furthermore, the effect of coadministration of this herb with modern drugs is not known though it is a known fact that this herb is frequently used along with modern drugs. On the contrary, myrrh is reported to increase the number of leucocytes in normal animals as well animals inflicted with skin wound or mild gastric ulcers induced by sodium chloride, indicating activation of cell mediated immunity, though the effect on healing of ulcer was not evaluated ${ }^{7}$. The effect on the number of leucocytes contributing to ulcer healing is not clear and it was proposed that the increase in number of leucocytes may have increase/decrease or no effect of healing of gastric ulcers. The present study was carried out to determine the effect of myrrh on chronic gastric ulcers induced by acetic acid and its effect on healing of gastric ulcers when co-administered with ranitidine, a known antiulcer agent. 


\section{MATERIALSAND METHODS}

\section{Materials}

Commiphora molmol oleo-gum-resin was purchased from local market in Riyadh (Saudi Arabia). It was identified and authenticated by Prof A M Sadabi, College of Applied Medical Sciences, Shaqra University (Saudi Arabia). A suspension of the myrrh was prepared in water by mixing finely powdered myrrh with water without addition of any suspending agent. This suspension was stored in refrigerator at $2-4^{\circ} \mathrm{C}$ until use.

\section{Preliminary phytochemical analysis}

The myrrh suspension was subjected to preliminary phytochemical screening using commonly used methods ${ }^{8,9}$.

\section{Animals}

Male Wistar albino rats weighing between 180-210 g were used. The animals were maintained under standard conditions of 12:12 h light dark cycle at a temperature of $25 \pm 2^{\circ} \mathrm{C}$. The experimental protocol was approved by the research committee of the institute for its ethical and scientific content.

\section{Acetic acid-induced chronic gastric ulcer}

The method reported by us earlier was followed ${ }^{10}$. Rats were fasted for $24 \mathrm{~h}$ prior to the induction of ulcer. Animals were lightly anesthetized and the abdomen was opened through a midline incision, made below the xiphoid process to expose the stomach. Glacial acetic acid $(0.05 \mathrm{~mL})$ was applied onto the serosal surface of the stomach using a cylindrical mould $(6 \mathrm{~mm})$ that was allowed to remain there for $60 \mathrm{~s}$. The mould was then rinsed using normal saline to remove the acid solution, to prevent possible damage to the surrounding tissues close to the point of application. The abdominal wall was closed by interrupted sutures. The animals were then divided into six different groups; the first group served as control and received vehicle while group 2 received ranitdine $(50 \mathrm{mg} / \mathrm{kg}, \mathrm{p} . \mathrm{o})^{10}$. The third and fourth group rats were treated with myrrh suspension at doses of $500 \mathrm{mg} / \mathrm{kg}$ or $1000 \mathrm{mg} / \mathrm{kg}$ body weight. The doses were selected from pilot studies. The last two groups received combination of myrrh (500 $\mathrm{mg} / \mathrm{kg}$ ) with ranidine (50 mg/kg, p.o) and myrrh $(1000 \mathrm{mg} / \mathrm{kg})$ with ranidine $(50 \mathrm{mg} / \mathrm{kg}, \mathrm{p} .0)$ respectively. Rats were killed $6 \mathrm{~h}$ after the last dose, stomach was removed and was cut open along the greater curvature. The total mucosal area and total ulcerated area were measured. The ulcer index was determined using the formula:

Ulcer index $=10$

$\mathrm{X}$

where $\mathrm{X}$ = total mucosal area/total ulcerated area.

The ulcers were assigned scores based on the intensity as follows; $0=$ no ulcer, $1=$ superficial lesion, $2=$ deep or penetrated ulcer and $3=$ perforated ulcer wherein the stomach is supported by surrounding tissues.

The ulcerated tissue was subjected to histopathological studies to determine the effect on surface epithelial tissue. The liver and kidney sections were also taken to determine the effect of treatments on these organs.

Statistical Analysis

Values are expressed as mean \pm standard error of mean (SEM). Statistical significance was determined by one-way analysis of variance (ANOVA) followed by Tukey's test for comparison of all parameters. Statistical significance for ulcer score was determined using Kruskal-Wallis test with post test. The statistical analysis was done using computer software (Graphpad lnstat DATASET 1, ISD, software version 3.0 for Windows). Values of $\mathrm{p}<0.05$ were considered to indicate statistical significance.

\section{RESULTS}

The phytochemical analysis of the myrrh suspension revealed presence of sesquiterpines (isoprenoids), sterols, steroids, furanoses quiterpenes, oxidase enzymes, ethanol soluble resins, tannins, acidic polysaccharides, alcoholsoluble resin, volatile oils, lindestrene and curzerenone.

Application of glacial acetic acid onto the serosal surface of the stomach led to development of penetrating ulcers in the control group. The ulcers were deep with scattered surface epithelium (seen only partially) as compared to stomach from normal animals (Fig. 1-2).

The standard ranitidine increased the ulcer healing as indicated by reduction in both ulcer score and the ulcer index (Table 1). Histological examination of the stomach from ranitidine treated animal revealed that there was regeneration of surface epithelium (Fig. 3).

Treatment with myrrh suspension at both 


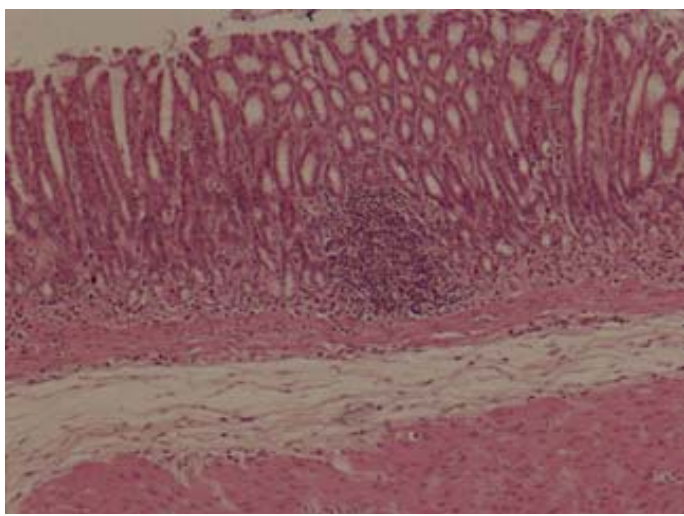

Fig. 1. Histology of stomach from untreated rat showing intact mucosa (100X)

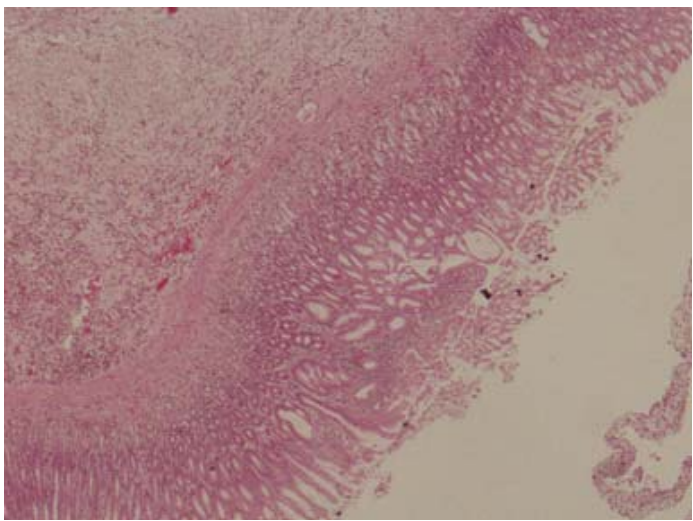

Fig. 3: Histology of stomach from rat treated with ranitidine $(50 \mathrm{mg} / \mathrm{kg}$, p.o) showing ulcerated area with regenerated epithelium (100X)

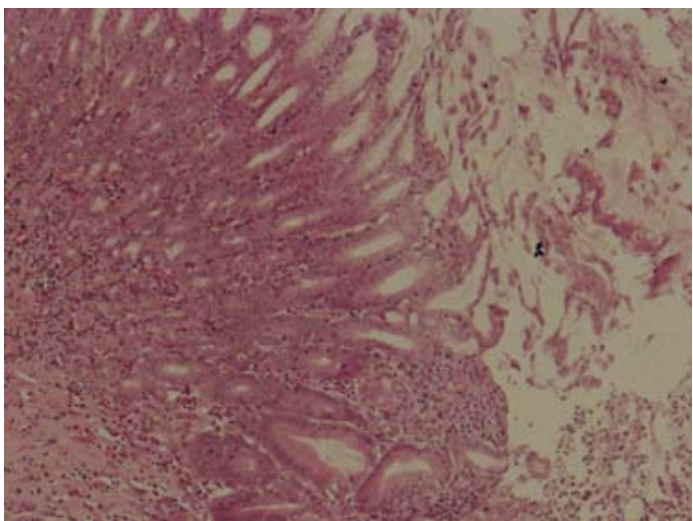

Fig. 5. Histology of stomach from rat treated with myrrh $(1000 \mathrm{mg} / \mathrm{kg}$, p.o) showing ulcerated area with regenerated epithelium (100X)

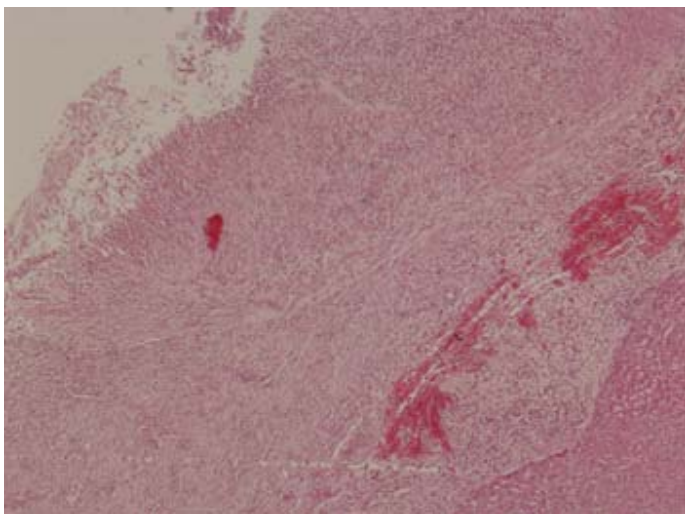

Fig. 2. Histology of stomach from control rat showing ulcerated area without any epithelium (100X)

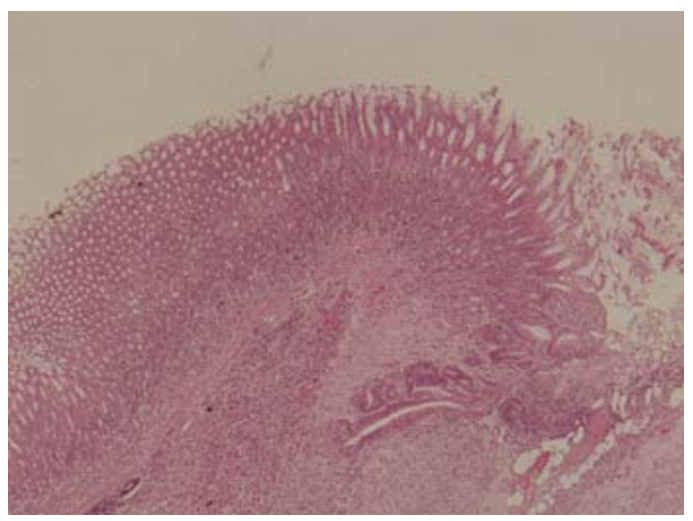

Fig. 4. Histology of stomach from rat treated with myrrh (500 mg/kg, p.o) showing ulcerated area with partially regenerated epithelium (100X)

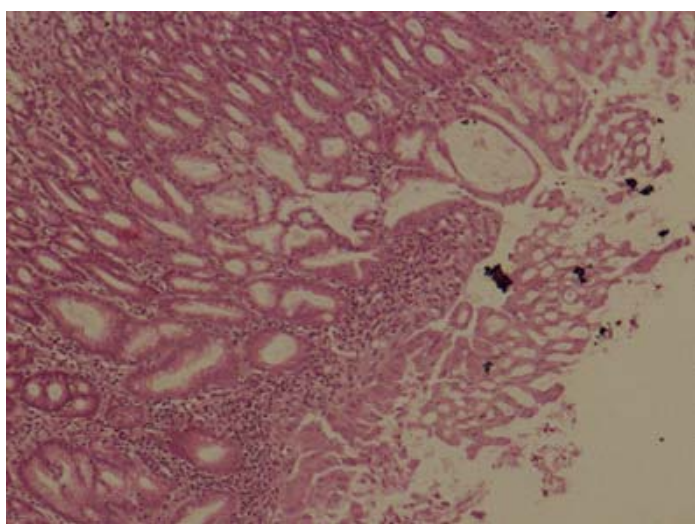

Fig. 6. Histology of stomach from rat treated with ranitidine and myrrh (500 mg/kg, p.o) showing ulcerated area with regenerated epithelium (100X) 
Table 1. Effect of Commiphora molmol water extract on different gastric ulcer models in rats

\begin{tabular}{llcc}
\hline \multirow{2}{*}{ Groups } & \multicolumn{2}{c}{ Acetic acid induced chronic gastric ulcers } \\
\cline { 2 - 4 } Control & Ulcer index & Ulcer score & Mortality \\
Ranitidine (50 mg/kg, p.o) & $0.52 \pm 0.031$ & $2.50 \pm 0.548$ & $1 / 7$ \\
Myrrh (500 mg/kg, p.o) & $0.22 \pm 0.026^{* * *}$ & $0.67 \pm 0.516^{*}$ & $0 / 6$ \\
Myrrh (1000 mg/kg, p.o) & $0.39 \pm 0.017^{* *}$ & $1.50 \pm 0.547$ & $1 / 7$ \\
Myrrh (500 mg/kg, p.o ) +Ranitidine (50 mg/kg, p.o) & $0.33 \pm 0.021^{* * *}$ & $0.83 \pm 0.753$ & $0 / 6$ \\
Myrrh (1000 mg/kg, p.o) + Ranitidine (50 mg/kg, p.o) & $0.09 \pm 0.014^{* * *}$ & $0.50 \pm 0.548^{*}$ & $0 / 6$ \\
\hline
\end{tabular}

All values are mean \pm SEM, $\mathrm{n}=6,{ }^{*} \mathrm{p}<0.05,{ }^{* *} \mathrm{p}<0.01,{ }^{* * *} \mathrm{p}<0.001$ compared to control. ${ }^{++} \mathrm{p}<0.01$ compared to ranitidine treated group.

doses (500 and $1000 \mathrm{mg} / \mathrm{kg}$ ) increased the ulcer healing when compared to the control group. The ulcerated area was less in both the myrrh treated groups that led to a significant decrease in ulcer index when compared to the control group. The ulcers were superficial and ulcer score was significantly less in myrrh treated group (1000 mg/ $\mathrm{kg}$ ) treated group compared to control group $(p<0.05)$. The macroscopic results were supported by histological findings; stomach of animals treated with myrrh had more surface epithelium indicating that ulcers were healed in group of animals treated with myrrh (Fig 4 and Fig 5).

The co-administration of ranitidine with myrrh (1000 mg/kg, p.o) significantly augmented the ulcer healing of ranitidine ( $<<0.01$ (Table 1$)$. Histological examination of the ulcerated tissues from animals of these groups showed that surface epithelium was completely regenerated epithelium (Fig 6 and Fig 7).

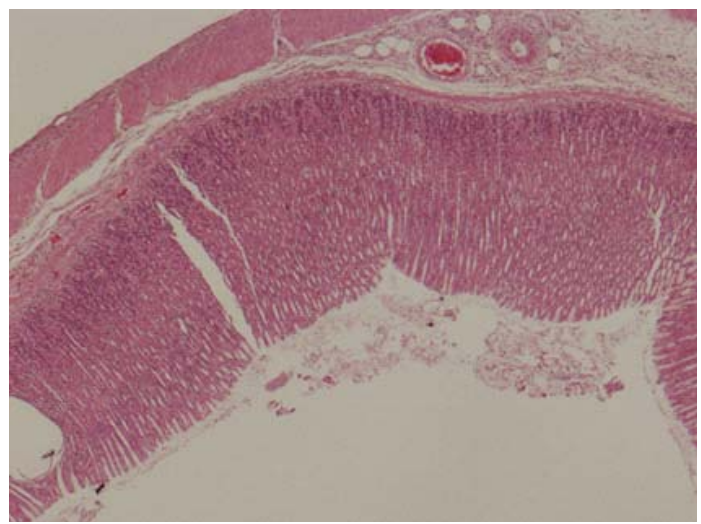

Fig. 7. Histology of stomach from rat treated with ranitidine and myrrh (1000 mg/kg, p.o) showing ulcerated area with regenerated epithelium (100X)

\section{DISCUSSION}

In the present study, administration of myrrh increased the healing of chronic gastric ulcers induced by acetic acid in rats. This is the first report on the ulcer healing effect of myrrh, which was reported earlier to prevent development of ulcers induced by necrotizing agents and pylorus ligation ${ }^{1}$. Furthermore, the findings of the present study provides further insight into the effect of myrrh on healing of sodium chloride induced ulcers, wherein the authors could not conclude the effect on ulcer healing due to an increased the number of leucocytes prior to ulcer development for four weeks and for two weeks after induction of ulcers may actually increase ${ }^{7}$.

Myrrh is one of the most widely used herbs in the Arabian countries and is commonly known as 'Balsam of Mecca' to show its importance in the Arabian society. As mentioned earlier, myrrh is reported to possess several pharmacological effects. The antiinflammatory, antipyretic and antihistaminic effects of C. $\mathrm{molmol}^{3}$ and hypolipidemic ${ }^{2}$, hypocholesteremic, antiartherosclerotic ${ }^{11}$ and antiarthritic potential ${ }^{12}$. Apart from that, the phytochemistry of myrrh has been extensively studied. It is reported to have volatile oils (up to $17 \%$ ), resins (up to $40 \%$ ), and gum (up to $60 \%$ ). The different volatile oils present include terpenes, sesquiterpenes, esters, cinnamaldehyde, cuminaldehyde, cumic alcohol, eugenol, heerabolene, limonene, dipentene, pinene, $\mathrm{m}$-cresol and cadinene were identified. The resins present include commiphoric acids, commiphorinic acid, herrabomyrrhols, heeraboresene, commiferin, ketosteroids, compesterol, fl-sitosterol, cholesteroletc $^{13}$. 
The mechanism of action for ulcer healing effect cannot be explained with the present data. However, earlier reports suggest that myrrh can influence ulcer healing through several mechanisms. It is known to increase mucus production, as well as nucleic acid production, and the concentration of non-protien sulfhydryl compound required for maintenance of gastroduodenal mucosa ${ }^{1}$. Myrrh is also reported to possess strong antioxidant effect that can also contribute to ulcer healing effect ${ }^{3}$. Myrrh is also known to possess strong antimicrobial effect. It is known to inhibit growth of different types of bacteria and fungi ${ }^{3}$. This antibacterial effect could also contribute to the increased ulcer healing observed with this herb.

Co-administration of high dose of myrrh with ranitidine augmented the antiulcer effect of ranitidine. This synergistic effect could be due to different mechanism of action of myrrh and ranitidine. As mentioned earlier, myrrh is reported to increase gastric mucus secretion, prostaglandin release and scavenge free radicals while ranitidine is a known antiulcer agent that reduces gastric acid secretion through its action on $\mathrm{H}_{2}$ histaminergic receptors in the stomach ${ }^{14}$. The gastric antisecretory effect of ranitidine along gastric cytoprotective effect of myrrh could have resulted in enhanced ulcer healing effect in the present study. In the present study, ranitidine was chosen over other known antiulcer agents because it is one of the oldest and most widely used antiulcer drugs. We propose that a similar effect may be observed when myrrh is consumed along with other gastric antisecretory agents from the same chemical class such as famotidine and probably with proton pump inhibitors such as omeprazole. However, it is difficult to predict the effect of co-administration of myrrh with gastric cytoprotective agents such as misoprostol, as they have the same mechanism of action and the effect could be additive or one agent may compete and antagonize the effect of other due to similar mechanism of action.

To conclude, myrrh increases healing of acetic acid induced chronic gastric ulcers in rats and it potentiates the ulcer healing of ranitidine in rats.

\section{REFERENCES}

1. Al-Howiriny, T., Al-Sohaibani, M., Al-Said, M., Al-Yahya, M., El-Tahir, K., Rafatullah, S. Effect of Commiphora opobalsamum (L.) Engl. (Balessan) on experimental gastric ulcers and secretion in rats. J. Ethnopharmacol. 2005; 98(3): 287-94.

2. Ramesh, B., Karuna, R., Sreenivasa, R.S., Haritha, K., Sai, M.D., Sasi, B.R., Saralakumari, D. Effect of Commiphora mukul gum resin on hepatic marker enzymes, lipid peroxidation and antioxidants status in pancreas and heart of streptozotocin induced diabetic rats. Asian Pac. J. Trop. Biomed. 2012; 2(11): 895-900.

3. Shen, T., Li, G.H., Wang, X.N., Lou, H.X. The genus Commiphora: a review of its traditional uses, phytochemistry and pharmacology. $J$. Ethnopharmacol. 2012; 142(2): 319-30.

4. Al-Harbi, M.M., Qureshi, S., Raza, M., Ahmed, M.M., Afzal, M., Shah, A.H. Gastric antiulcer and cytoprotective effect of Commiphora molmol in rats. J. Ethnopharmacol. 1997; 55(2): 141-50.

5. Gao, W., Su, X., Dong, X., Chen, Y., Zhou, C., Xin, P., Yu, C., Wei, T. Cycloartan-24-ene1á,2á,3â-triol, a cycloartane-type triterpenoid from the resinous exudates of Commiphora myrrha, induces apoptosis in human prostatic cancer PC-3 cells. Oncol. Rep. 2015; 33(3): 1107-1114.

6. Walsh, M.E., Reis, D., Jones, T. Integrating complementary and alternative medicine: use of myrrh in wound management. J. Vasc. Nurs. 2010; 28(3): 102.

7. Haffor ,A.S. Effect of Commiphora molmol on leukocytes proliferation in relation to histological alterations before and during healing from injury. Saudi J. Biol. Sci. 2010; 17(2): 139-46.

8. Finar, I.L. (ed): Organic Chemistry. 4th ed.; Pearson: New Delhi, 1993.

9. Mukherjee, P.K. (ed): Quality Control of Herbal Drugs; an Approach to Evaluation of Botanicals. Business Horizons Pharmaceutical Publishers: New Delhi, 2002.

10. Asad, M., Shewade, D.G., Koumaravelou, K., Abraham, B.K., Vasu, S., Ramaswamy, S. (2001). Gastric anti-secretory and anti-ulcer activity of oxytocin in rats and guinea pigs. Life Sci. 2001; 70: 17-24.

11. Siddiqui, M.Z., Mazumder, P.M. Comparative Study of Hypolipidemic Profile of Resinoids of Commiphora mukul/Commiphora wightii from Different Geographical Locations. Indian J. Pharm. Sci. 2012; 74(5): 422-7. 
12. Mehta, A.K., Tripathi, C.D. Commiphora mukul attenuates peripheral neuropathic pain induced by chronic constriction injury of sciatic nerve in rats. Nutr. Neurosci. 2015; 18(3): 97-102

13. Evans, W.C. (ed): Trease and Evans pharmacognosy. Elsevier health sciences,New jersey, USA, $16^{\text {th }}$ edition, 2009

14. Hoogerwerf, W.A., Pasricha, P.J. Agents used for the control of gastric acidity and treatment of peptic ulcers and gastro oesophageal reflux diseases. In: Hardman JG, Limbrid LE, Goodman CS, Gilman BT. (Editors.). Goodman and Gilman's. The Pharmacological Basis of Therapeutics. $10^{\text {th }}$ ed, New York: McGraw-Hill; 2001; 1005-19 